\title{
Verification of a Rapid Mooring and Foundation Design Tool
}

\author{
S.D. Weller ${ }^{1}$, J. Hardwick ${ }^{1}$, S. Gomez ${ }^{2}$, J. Heath², R. Jensen², N. McLean ${ }^{3}$, L. Johanning ${ }^{1}$. \\ ${ }^{1}$ (Renewable Energy, College of Engineering, Mathematics and Physical Sciences), University of Exeter, \\ Penryn Campus, UK \\ ${ }^{2}$ Sandia National Laboratories, New Mexico, Albuquerque, USA \\ ${ }^{3}$ Tension Technology International Ltd, Eastbourne, Sussex, UK \\ Corresponding author
}

S.D. Weller, Renewable Energy, College of Engineering, Mathematics and Physical Sciences, University of Exeter, Penryn Campus, Penryn, Cornwall UK TR10 9EZ

Email: $\underline{\text { S.Weller@exeter.ac.uk }}$

\section{ABSTRACT}

Marine Renewable Energy (MRE) devices require mooring and foundation systems that are suitable in terms of device operation, are robust and also cost effective. In the initial stages of mooring and foundation development a large number of possible configuration permutations exist. Filtering of unsuitable designs is possible using information specific to the deployment site (i.e. bathymetry, environmental conditions) and device (i.e. mooring and/or foundation system role and cable connection requirements). The identification of a final solution requires detailed analysis, which includes load cases based on extreme environmental statistics following certification guidance processes. Static and/or quasi-static modelling of the mooring and/or foundation system serves as an intermediate design filtering stage enabling dynamic time-domain analysis to be focused on a small number of potential configurations.

Mooring and foundation design is therefore reliant on logical decision making throughout this stagegate process. The open-source DTOcean (Optimal Design Tools for Ocean Energy Arrays) Tool includes a Mooring and Foundation (MF) module, which automates the configuration selection process for fixed and floating wave and tidal energy devices. As far as the authors are aware this is one of the first tools to be developed for the purpose of identifying potential solutions during the initial stages of MRE design. Whilst the MF module does not replace a full design assessment, it provides in addition to suitable configuration solutions, assessments in terms of reliability, economics and environmental impact. This paper provides insight into the solution identification approach used by the module and features the verification of both the mooring system calculations and the foundation design using commercial software. Several case studies are investigated; a floating wave energy converter and several anchoring systems. It is demonstrated that the MF module is able to provide device and/or site developers with rapid mooring and foundation design solutions to appropriate design criteria.

\section{Keywords}

Marine Renewable Energy; DTOcean; Quasi-static analysis; Mooring system; Foundation; Anchor; Verification; 


\section{Introduction}

Economies of scale dictate that in order for electricity generation from wave and tidal energy to be commercially competitive with conventional generation methods, arrays comprising $10 \mathrm{~s}-100 \mathrm{~s}$ of devices are required. To-date only a few of array demonstration projects have included open-water field trials with arrays comprising less than 50 devices, for example Nova Innovation (300kW total; Shetland, UK), DCNS (1MW total; Paimpol-Bréhat, France), Carnegie Clean Energy (720kW total; Perth, Australia) and Seabased (1MW total; Sotenäs, Sweden). The rollout of projects with larger generation capacity is at present limited to arrays of tidal energy devices, for example the MeyGen Phase $1 \mathrm{~A}$ project ( $6 \mathrm{MW}$ total; Pentland Firth, Scotland). These, and other projects are motivated by the globally significant worldwide wave and tidal resource. The UK's Department for Business, Energy \& Industrial Strategy estimated in 2013 [1] that MRE devices can meet up to $20 \%$ of the UK's current electricity demand (equivalent to 30-50GW of installed capacity). The marine renewable energy (MRE) industry is however nascent and there is considerable development needed before it becomes a key player in the electricity generation mix. In the context of ambitious cost reduction targets (i.e. an overall cost of energy of $f 0.07-f 0.10 / \mathrm{kWh}$ by 2030 [2]) developers are faced with two intrinsically linked challenges; i) ensuring sufficient device performance over a wide range of conditions and ii) favourable availability between maintenance intervals. The environmental impact of technologies is also an important consideration as it is often a requirement of the site consenting process. It is estimated to cost between $€ 50 \mathrm{~m}$ to $€ 100 \mathrm{~m}$ [3] to take a design from concept to a single functional prototype. The design of hardware (i.e. devices, moorings and/or foundation systems and electrical architecture) and planning of operations (i.e. installation, decommissioning and maintenance) will therefore have a direct impact on how long it will take for the project's CAPEX and OPEX to be recuperated and hence long-term project economies.

\section{DTOcean Tool Overview}

In the early stages of planning arrays of MRE devices, there are a large number of possible design permutations, which if analysed separately would require significant computational time. Broadly there are three cross-cutting assessment criteria that can be used to determine the feasibility of aforementioned design hardware and operations: i) LCoE (Levelised Cost of Energy), ii) reliability and iii) environmental impact. Under the European Commission 7th Framework ENERGY 2013-1 call the Optimal Design Tools for Ocean Energy Arrays (DTOcean) project developed a system-level tool for assessing the three feasibility criteria for the first generation of MRE device arrays. Several key aspects are analysed by the Tool using integrated modules including; array layout, electrical system architecture, mooring and foundation systems as well as lifecycle logistics (including array maintenance and operation), with the modules supported by a customisable database. Coded in the Python 2.7 programming language and hosted by the European Commission [4], the software and supporting database are open-source allowing a community of users to use and/or adapt the source code for their own requirements. Whilst this is not the first piece of software that has been developed for mooring design (e.g. OPTIMOOR [5]) or array planning (e.g. SI-Ocean [6]), as far as the authors are aware it is the first integrated design tool that: i) captures several key aspects of MRE array design, ii) includes a database which is customisable and iii) is open-source. It is the objective of this paper to report results of verification comparisons between the MF module and mooring analysis (Orcaflex [7]) and finite element software (CUBIT [8] and Sierra/SM [9]) software programs. 


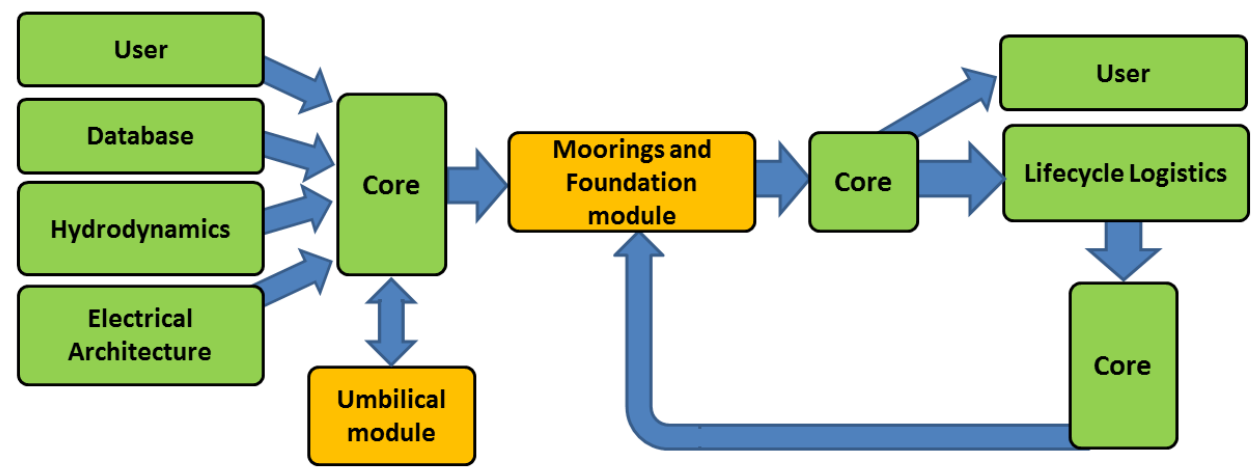

Figure 1. Dataflow through the DTOcean Tool.

At the centre of the Tool architecture is a Core which links the modules, database and graphical user interface (GUI). A schematic is displayed in Figure 1 with respect to the mooring and foundation (MF) module, which is the focus of the following sections.

\section{Mooring and Foundation (MF) Design Module}

The MF module is designed as a preliminary analysis and precursor to more detailed, fully dynamic simulations carried out using commercial systems-based software packages or bespoke codes. The purpose of the DTOcean MF module is to perform static and quasi-static analysis to develop mooring and foundation solutions that:

- $\quad$ are suitable for a given site, the MRE device (and substation), and expected loading conditions;

- retain the integrity of the electrical umbilical that connects the MRE device to the subsea cable (floating devices);

- are spatially compatible with the array layout;

- where practicable fulfil the requirements and/or constraints determined by the user and/or in terms of reliability and/or environmental concerns; and

- have the lowest capital cost.

\section{Module methodology}

The MF module is designed to have a modular structure. This increases speed and reduces the computing power needed as not all scenarios will require every part of the module to be used [10], e.g. if the user has already identified a mooring system then the foundation sub-module can be used to focus just on the anchoring system design. For a more detailed explanation of the MF module structure and processing stages the reader is directed to the Technical Manual [11].

It is understood by the authors that dynamic coupling between mooring and wave loads on a moored vessel or device can have an impact on both the maximum device excursions and maximum line loads particularly if dynamic amplification of the moored device motion response is significant. This is accounted for, to an extent, in conventional quasi-static analysis by solution of the equation of motion in the frequency domain for first- and second order-wave loads but not in the MF mooring module calculations described.

These limitations are a consequence given through the objectives from the DTOcean Tool development, which were primarily focused on the LCOE prediction of array installations, and with specific requirements towards analysis speed. It is not claimed that the MF module provides full capabilities of typical quasi-static analysis approaches (e.g. [12]). Hence the presented comparison is 
essentially intended to inform users about possible implications related to outputs in comparison to industry quasi-static analysis tools, and how the MF module predictions should be used in context of a comprehensive engineering mooring design approach.

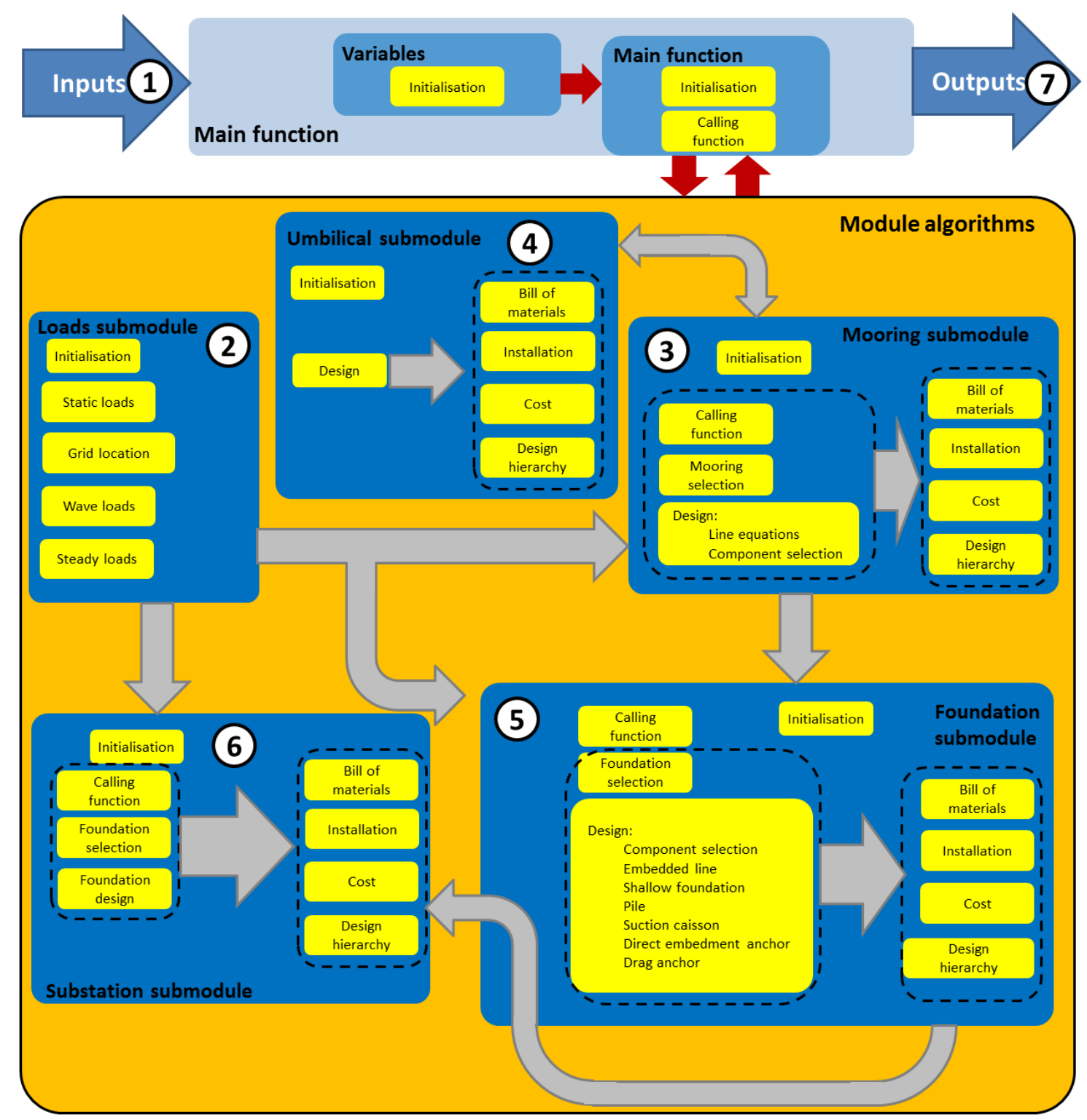

Figure 2. Simplified dataflow within the MF module.

Figure 2 presents a graphical representation of the dataflow through the MF module. Referring to the number labels in this figure, the following calculation stages are used:

1. The complexity of designing a mooring and foundation system means that there are potentially a large number of input variables required in order conduct mooring analysis. To reduce these, the MF module database contains default values for certain variables that can be overwritten by the user if information is known. Some of these variables are used throughout the DTOcean suite (e.g. site bathymetry, certain device parameters) whereas others are specific to the MF module (e.g. seafloor soil conditions). The variables can be broadly defined by four categories:

- Device variables: e.g. device dimensions, profile, locations of fairlead points (floating devices), centre of gravity, first-order wave excitation transfer functions 
- Environmental variables: e.g. current speed, wave parameters, wind speed

- Seafloor variables: e.g. bathymetry, soil type, friction coefficients

- User defined parameters: e.g. maximum allowed displacement, pre-defined mooring or foundation constraints

2. The Loads submodule uses input parameters to first check that all devices are positioned within the bathymetry grid and then determines the environmental loads applied to the device and, if relevant, the support structure. If first-order wave forces are provided either from the DTOcean hydrodynamics module or by the user (i.e. from WAMIT/NEMOH analysis) then these forces are combined with the current $\left(1 / 7^{\text {th }}\right.$ power law or uniform profile) and wind forces to produce the total applied loads on the device. If load coefficients are not provided then, depending on the device dimensions and wave conditions, the loads are calculated using either a diffraction theory approximation and a F-K force coefficient approach $[13,14,15,16$, $17,18,19]$ or by solving the Morison equation $[20,21,13]$. Depending on the device operation, mean drift is estimated using several approaches; fixed vertical cylinders [22], floating vertical cylinders [23] and fixed/floating cuboids [24]. Coefficients for drag and added mass are taken from several sources $[25,26]$. Warnings are displayed if the calculations involve parameters outside of the range applicable to the theories or experimental data used.

3. For floating devices the Mooring submodule is used to select components from the DTOcean (or other user provided) database and then calculate mooring line tensions (using an approach similar to that reported by Masciola [27]) to determine if the assembled mooring system is suitable for the loads applied to the device. Both catenary and taut mooring systems can be analysed by the MF module. The device equilibrium position is calculated by adjusting the displacement of the device until the translational $(\mathrm{X}, \mathrm{Y}$ and $\mathrm{Z}$ ) force balance is achieved. If the calculated line tensions are below the minimum break load (MBL) of the components (including specified factors of safety; FOS [12]) and the final position is within the user specified excursion limits then the mooring system is deemed to be acceptable. If either of these conditions is violated in either the Ultimate Limit State (ULS) or the Accident Limit State (ALS; with one line removed) then one or more new components are selected and the process is repeated. If no suitable configuration can be found using components in the program's database then the Tool will increase the number of mooring lines and restart the calculation process.

4. A critical part of a floating MRE device is the power cable or umbilical. Within the Umbilical submodule a lazy-wave geometry is defined, and tensions and bend radii are determined based on the position of the device during ULS from the Mooring submodule. Checks are carried out within the submodule to ensure that the calculated tensions do not exceed the specified MBL of the umbilical and the minimum bend radius limit is not violated. Once these checks are passed details regarding the umbilical length and required flotation are output.

5. For floating devices the loads on the anchors are an output of the mooring design calculations whereas for fixed devices the foundation loads are calculated from the forces applied to the device and support structure. Depending on user-defined criteria, seabed bathymetry and geotechnics as well as device characteristics the module will select one or more anchor/foundation types from the following list: drag embedment, direct embedment, gravity-based, piles, suction caissons and shallow foundations. The design of the foundation is determined from a series of analytical calculations to ensure that the holding capacity is sufficient to support the expected loads $[28,29,30,31,32,33]$. If more than one type of foundation is suitable then the lowest cost solution is identified. The user is given the option of forcing the tool to produce uniform foundations or allowing multiple types across the array. 
6. MRE device arrays, like farms of offshore wind turbines, typically have one or more substations to transfer power back to the shore. This equipment also requires a foundation and two types are covered by the MF module; piles for above surface substations and gravity foundations for subsea systems. Instead of repeating code in the MF module, the Substation submodule calls the relevant functions within the Foundation submodule.

7. The outputs of the MF module are collated by the Core for use by the other modules and/or are displayed to the User.

\section{Verification using Test Scenarios}

As part of the DTOcean Tool development process the outputs of the MF module were verified using commercial software (mooring systems; Orcaflex and foundation systems; CUBIT and Sierra/SM). Example results are presented in the following subsections and for further information the reader is directed to DTOcean Deliverable 7.3 [34]. An overview of the verification process is provided in Figure 3.
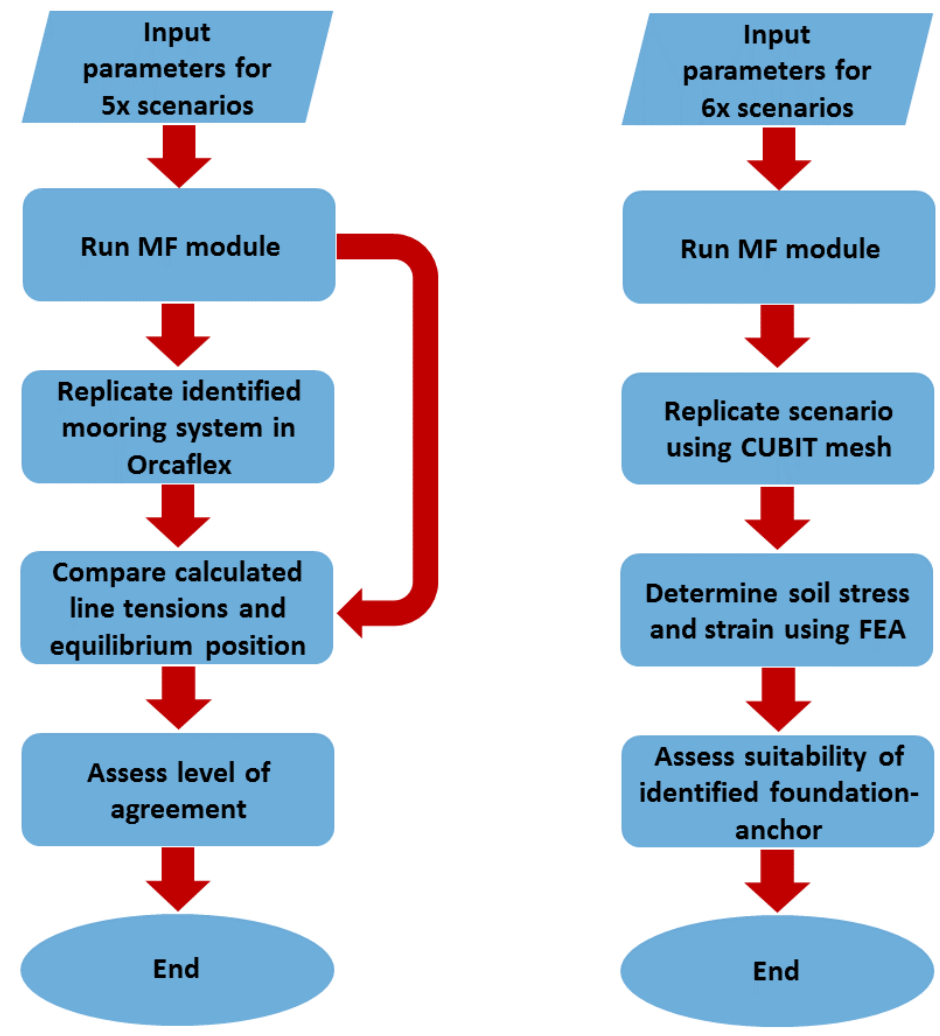

Figure 3: The verification process summarised for (left) floating and (right) fixed device scenarios.

\section{Numerical verification of mooring systems}

To carry out basic verification of the DTOcean MF module calculations, the module was used to design moorings for a floating cylinder, referred to as the 'bean can model' (Table 1), representing a floating wave energy converter subjected to the five scenarios listed in Table 2. Selected load cases and environmental condition parameters: $\mathrm{HmO}$ (significant wave height), $\mathrm{Tp}$ (peak period) and Dir (direction).Table 2. These scenarios were selected from a list of 50 based on design environmental conditions at potential Shetland farm sites and possible mooring configurations (e.g. mooring systems with specific footprints and either catenary chain or taut polyester lines). 
After running the DTOcean MF module calculations for each scenario, a static verification of the calculated device position and mooring line tension was performed by taking the total environmental load calculated by MF Loads submodule and identified mooring system and replicating the static analysis in Orcaflex for both the ULS and ALS scenarios. Comparison of the device excursion and line tensions estimated by Orcaflex and the MF module for each scenario for the ULS and ALS events are tabulated in Table 3.

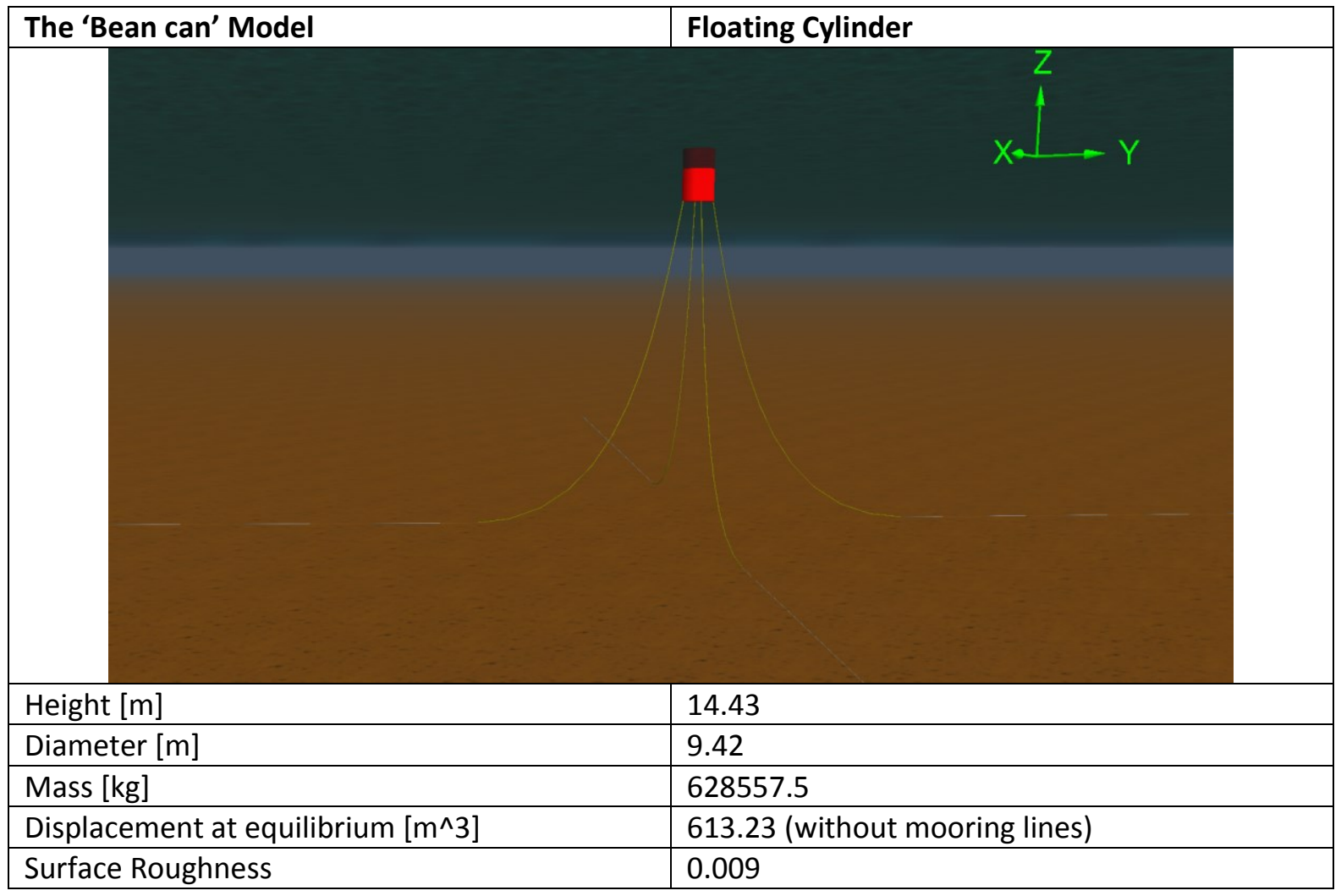

Table 1. Parameters of the 'bean can' WEC model.

\begin{tabular}{|c|c|c|c|c|c|c|c|c|c|c|c|}
\hline \multirow{2}{*}{ 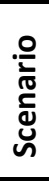 } & \multicolumn{4}{|c|}{ Wave (Direction from) } & \multicolumn{2}{|c|}{$\begin{array}{l}\text { Current } \\
\text { (Direction to) }\end{array}$} & \multicolumn{2}{|c|}{$\begin{array}{l}\text { Wind (Direction } \\
\text { from) }\end{array}$} & \multirow{2}{*}{$\begin{array}{l}\text { Water } \\
\text { depth } \\
\text { (m) }\end{array}$} & \multirow{2}{*}{$\begin{array}{l}|x|=|y| \\
(m)\end{array}$} & \multirow{2}{*}{$\begin{array}{l}\text { Mooring } \\
\text { system type }\end{array}$} \\
\hline & $\begin{array}{l}\mathrm{HmO} \\
(\mathrm{m})\end{array}$ & $\begin{array}{l}\text { Tp } \\
\text { (s) }\end{array}$ & $\begin{array}{l}\text { Dir } \\
\left({ }^{\circ} \mathrm{N}\right)\end{array}$ & $v(-)$ & $\begin{array}{l}\text { Speed } \\
(\mathrm{m} / \mathrm{s})\end{array}$ & $\begin{array}{l}\text { Dir } \\
\left({ }^{\circ} \mathrm{N}\right)\end{array}$ & $\begin{array}{l}\text { Speed } \\
(\mathrm{m} / \mathrm{s})\end{array}$ & $\begin{array}{l}\text { Dir } \\
\left({ }^{\circ} \mathrm{N}\right)\end{array}$ & & & \\
\hline 1 & 13 & 14.8 & 90 & 3.3 & 0.7 & 135 & 39.8 & 120 & 100 & 188.573 & Catenary Chain \\
\hline 2 & 13 & 14.8 & 90 & 3.3 & 0.7 & 135 & 39.8 & 120 & 100 & 364.221 & Taut Polyester \\
\hline 3 & 13 & 14.8 & 90 & 3.3 & 0.7 & 135 & 39.8 & 120 & 50 & 196.687 & Catenary Chain \\
\hline 4 & 13 & 14.8 & 90 & 3.3 & 0.7 & 135 & 39.8 & 120 & 50 & 233.648 & Taut Polyester \\
\hline 5 & 10.48 & 14.8 & 90 & 3.3 & 0.7 & 135 & 39.8 & 120 & 25 & 124.509 & Taut Polyester \\
\hline
\end{tabular}

Table 2. Selected load cases and environmental condition parameters: $\mathrm{Hm} 0$ (significant wave height), $\mathrm{Tp}$ (peak period) and Dir (direction). 


\begin{tabular}{|c|c|c|c|c|c|c|c|c|c|c|c|}
\hline \multirow{2}{*}{\multicolumn{2}{|c|}{$\begin{array}{l}\text { Case } \\
\text { Limit State }\end{array}$}} & \multicolumn{2}{|l|}{1} & \multicolumn{2}{|l|}{2} & \multicolumn{2}{|l|}{3} & \multicolumn{2}{|l|}{4} & \multicolumn{2}{|l|}{5} \\
\hline & & ULS & ALS & ULS & ALS & ULS & ALS & ULS & ALS & ULS & ALS \\
\hline \multicolumn{2}{|l|}{ Number of Lines } & 4 & 4 & 4 & 4 & 7 & 7 & 4 & 4 & 4 & 4 \\
\hline \multicolumn{2}{|l|}{ Line Length (m) } & 320.76 & 320.76 & 518.9 & 518.9 & $*$ & $*$ & 328.69 & 328.69 & 172.48 & 172.48 \\
\hline \multicolumn{2}{|c|}{$\begin{array}{l}\text { Line weight per unit length } \\
(\mathrm{N} / \mathrm{m})\end{array}$} & 1411.5 & 1411.5 & 183.84 & 183.84 & 1412.5 & 1412.5 & 234.06 & 234.06 & 263.61 & 263.61 \\
\hline \multicolumn{2}{|c|}{$\begin{array}{l}\text { Axial Stiffness at } \\
\text { equilibrium position }(\mathrm{kN})\end{array}$} & 662811 & 662811 & 37088 & 37088 & 662826 & 662826 & 38807 & 38807 & 37981 & 37981 \\
\hline \multicolumn{12}{|c|}{ DTOcean Module Results } \\
\hline \multirow{3}{*}{$\begin{array}{l}\text { Equilibrium Position } \\
\text { (m) }\end{array}$} & $x$ & 0.13 & 0.13 & 0.12 & 127.01 & 0.22 & 12.92 & 0.62 & 75.9 & 0.37 & 41.48 \\
\hline & $\mathrm{Y}$ & 53.8 & 53.8 & 49.53 & 140.5 & 15.72 & -1.74 & 17.87 & 85.17 & 9.47 & 39.46 \\
\hline & $\mathrm{Z}$ & 5.71 & 5.71 & 4.95 & 5.07 & 5.58 & 5.84 & 4.96 & 5.21 & 5.4 & 5.92 \\
\hline \multirow[t]{7}{*}{ Line Tension (kN) } & 1 & 134.49 & 133.03 & 6.6 & 3.1 & 78.1 & 132.17 & 16.23 & 4.35 & 14.03 & 28.97 \\
\hline & 2 & 134.61 & 2285.2 & 6.64 & 584.21 & 116.41 & 119.64 & 17.89 & 1743.4 & 15.86 & 2215.9 \\
\hline & 3 & 1471.6 & 4060 & 1418.2 & 3310.6 & 179.51 & 86.27 & 1721.8 & 4069.2 & 1864.5 & 5636.5 \\
\hline & 4 & 1557.1 & N/A & 1493.1 & N/A & 1403.7 & 3720.6 & 1797.8 & N/A & 1952 & $\mathrm{~N} / \mathrm{A}$ \\
\hline & 5 & & & & & 1523.2 & $\mathrm{~N} / \mathrm{A}$ & & & & \\
\hline & 6 & & & & & 185.54 & 462.26 & & & & \\
\hline & 7 & & & & & 118.26 & 1423.1 & & & & \\
\hline \multicolumn{12}{|l|}{ Orcaflex Results } \\
\hline \multirow{3}{*}{$\begin{array}{l}\text { Equilibrium Position } \\
\text { (m) }\end{array}$} & $x$ & 0.16 & 106.94 & 2.06 & 162.2 & -0.59 & 7.00 & 0.47 & 73.84 & 0.29 & 39.78 \\
\hline & $\mathrm{Y}$ & 58 & 111.61 & 76.35 & 192.82 & 17.77 & 21.98 & 14.04 & 85.16 & 8.02 & 45.96 \\
\hline & $\mathrm{Z}$ & -5.65 & -4.98 & -5.01 & -5.11 & -5.74 & -5.36 & -4.92 & -5.01 & -5.11 & -5.06 \\
\hline \multirow[t]{7}{*}{ Line Tension (kN) } & 1 & 145.86 & 157.53 & 24.96 & 21.42 & 181.89 & 177.13 & 35.63 & 12.38 & 11.21 & 4.96 \\
\hline & 2 & 146.01 & 792.05 & 26.6 & 987.23 & 80.59 & 64.97 & 39.1 & 1923.6 & 13.08 & 2019.8 \\
\hline & 3 & 1442.3 & 2545 & 1385.4 & 2624.7 & 261.81 & 223.50 & 1747.2 & 3777 & 1860.1 & 4030.6 \\
\hline & 4 & 1522.5 & N/A & 1450 & N/A & 1683.15 & 2672.19 & 1821.9 & N/A & 1948.4 & N/A \\
\hline & 5 & & & & & 1398.07 & $\mathrm{~N} / \mathrm{A}$ & & & & \\
\hline & 6 & & & & & 318.71 & 1176.65 & & & & \\
\hline & 7 & & & & & 203.72 & 214.69 & & & & \\
\hline
\end{tabular}

Table 3. Parameters of mooring system designed by the DTOcean MF module. The symbol * denotes line lengths in the range of $290.48-299.34 \mathrm{~m}$. 

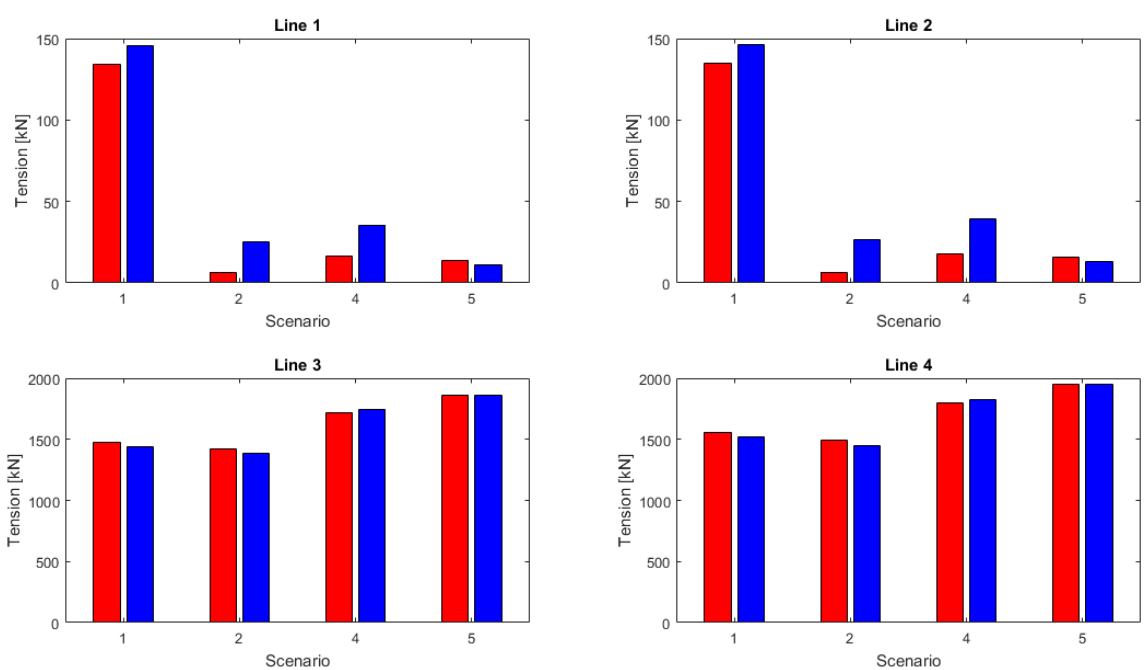

(a)
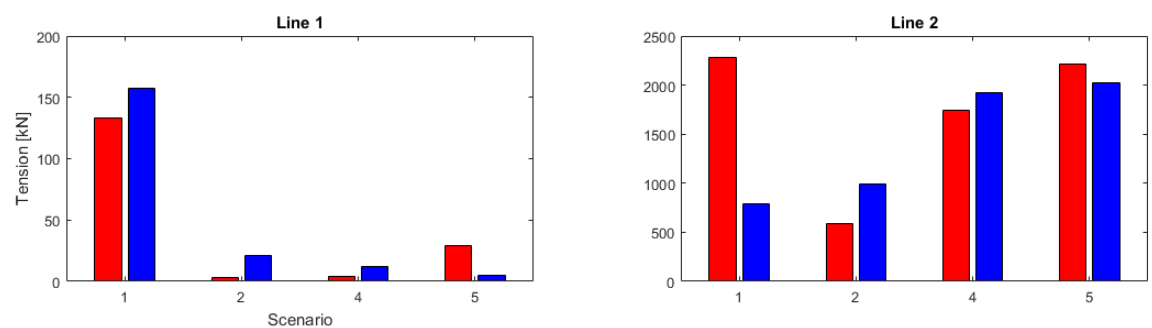

(b)
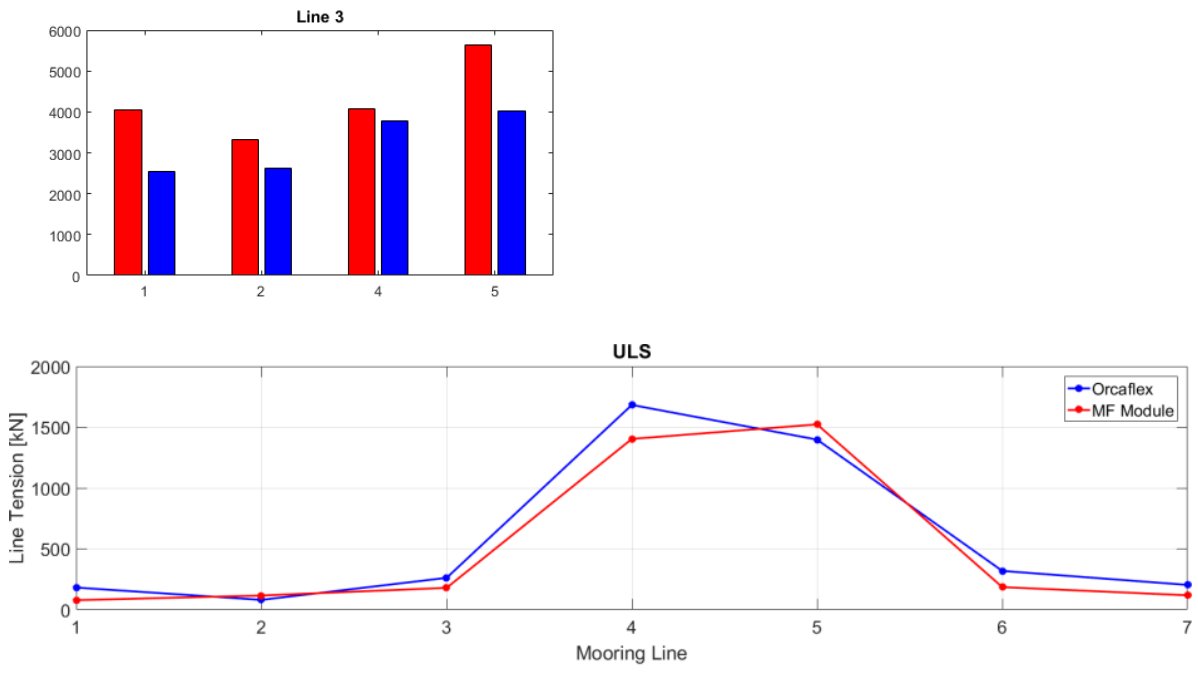

ALS

(c)

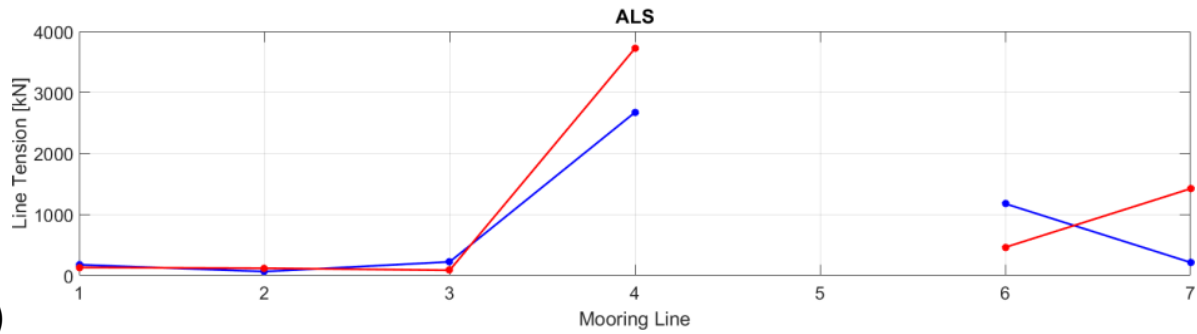

Figure 4. Comparison between static solutions from the MF module (red lines/bars) and Orcaflex (blue lines/bars) for Scenarios 1, 2, 4 and 5 a) ULS and b) ALS scenarios. c) Comparison for Scenario 3. Note: scaling on each y-axis.

The MF module successfully provided a mooring and foundation solution for all five scenarios. For Scenario 1, 2, 4 and 5 an acceptable mooring configuration was identified using four lines configuration identified as module input. For Scenario 3 however no four line solution was available 
and the module determined that this particular scenario required a configuration with seven mooring lines. The solutions provided by the module can be seen in Table 3 with comparisons made to Orcaflex static simulations in Figure 4.

\section{Numerical verification of foundation-anchor systems}

Verification of foundation-anchor algorithms of the MF module was performed using finite element analysis (FEA). The algorithms were based on analytical solutions from references [28, 29, 30, 31]. Since the purpose of the DTOcean Tool is to provide scoping estimates of cost, the main goal of the foundation-anchor algorithms is to determine reasonable designs for cost estimation. The FEA is intended to verify that the designs are adequate to support specified load requirements. The FEA procedure focuses on worst case loading scenarios for suction caisson, direct embedment foundationanchor, pile foundation-anchor, and shallow gravity foundation-anchor designs produced by MF module. To investigate foundation-anchor response as function of seafloor geomaterials, the foundation-anchors are assumed to be emplaced in various sediments or rock, including soft clay, dense sand, loose sand, and hard rock.

Model development for the FEA was created using output from the MF module, which provided soil (used as a general term to refer to seafloor sediments or rock) and foundation-anchor system material properties, basic foundation-anchor system geometry, as well as boundary conditions on the soil. Six different cases were run using the MF module program to calculate the aforementioned parameters as shown in Table 4.

The simulations implemented different loading scenarios and geometry on the varying foundationanchor system geometry. The base case scenario is a floating wave energy device, loosely based on Pelamis. The environmental conditions of the tidal turbines were computed by the MF module and translated into mooring line loads that were then used by the MF module to select the required size and geometry of the respective foundation-anchors. The MF module's foundation-anchor geometries and soil types (Table 4), in addition to the structural loads calculated at the anchor end of the mooring lines were used as the input parameters for the FEA simulations.

\begin{tabular}{|l|l|l|}
\hline Simulation & Soil Type & Foundation-anchor Type \\
\hline Sim1 & Soft Clay & Suction Caisson \\
\hline Sim2 & Dense Sand & Direct Embedment \\
\hline Sim3 & Soft Clay & Pile (Rev1) \\
\hline Sim4 & Soft Clay & Pile (Rev2) \\
\hline Sim5 & Soft Clay & Shallow (Rev1) \\
\hline Sim6 & Soft Clay & Shallow (Rev2) \\
\hline
\end{tabular}

Table 4. MF module simulations.

\section{Finite Element Model}

The FEM pre-processor, CUBIT, was used for mesh generation. Mesh simplifications were made to the defined parameters in effort to reduce computational cost and allow for increased refinement near stress areas of interest. All foundation-anchor meshes are shown in Figure 5. To mitigate loading boundary effects, the soil was represented to a distance of 20 times the casing diameter and a depth of one times the respective embedment and pile foundation-anchor depth. Axisymmetric geometry 
was implemented to reduce computational cost. The material model used for the soil is the Soil and Crushable Foam material model, which was originally formulated by Krieg [35] and is currently implemented in Sierra/SM, based on PRONTO 3D [36].

(a)

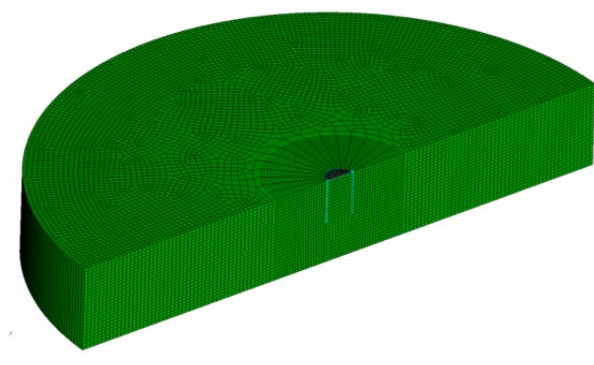

(c)
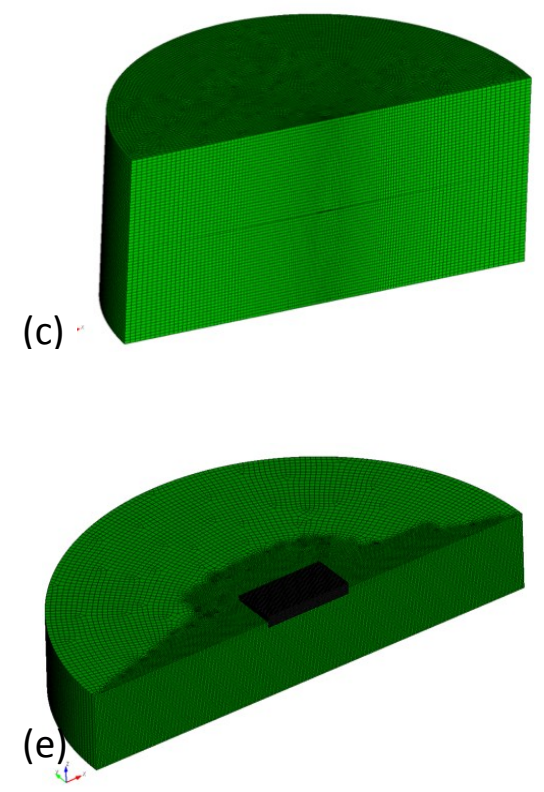

(g)

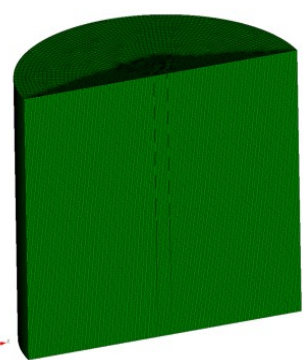

(b)

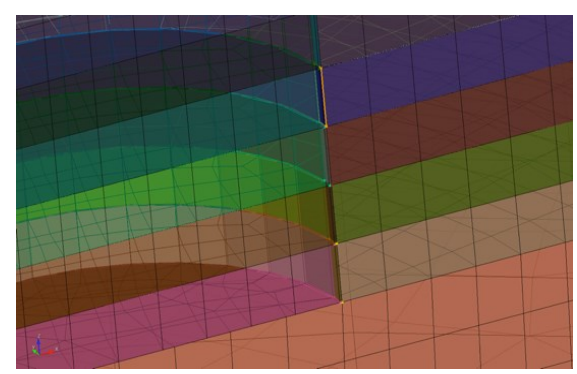

(d)

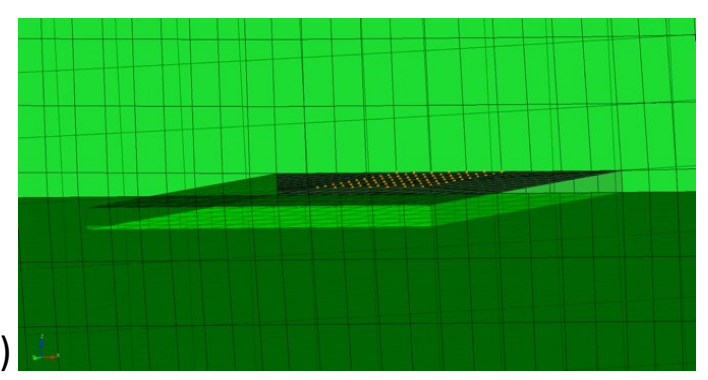

(f)

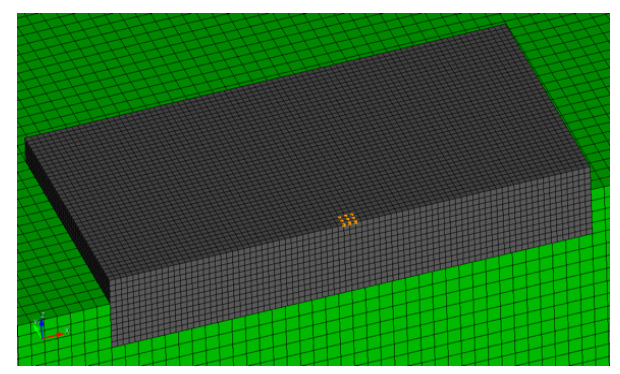

(h)

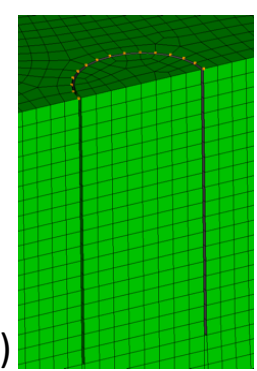

Figure 5. Full mesh of the suction caisson configuration shown in (a) isometric view, (b) load location of the representative caisson pad eye, (c) full mesh of the direct embedment foundation-anchor configuration shown in isometric view, (d) load location of the representative foundation-anchor plate pad eye, (e) full hex mesh of the shallow gravity foundation configuration shown in isometric view, (f) load location of the representative foundation-anchor pad eye, (g) full mesh of the pile foundation-anchor design configuration shown in isometric view, and (h) load location of the representative pile pad eye.

Model parameters. The foundation-anchor system design parameters used in the FEA are shown in Table 5 - Table 8. The embedment foundation-anchor and shallow gravity foundation-anchor pad eyes were located in the middle of the foundation-anchor plate, axisymmetric across the cross-section. 


\begin{tabular}{|l|l|l|}
\hline Definition & Units & Value: Sim1 \\
\hline Caisson diameter & $\mathrm{m}$ & $5 \times 3.5$ \\
\hline Caisson length & $\mathrm{m}$ & $7.925 \times 5.5$ \\
\hline Caisson thickness & $\mathrm{m}$ & $0.0254 \times 0.06$ \\
\hline Padeye load & $\mathrm{N}$ & $1.353111 \mathrm{E}+6$ \\
\hline Angle & Degrees & 0 \\
\hline Pad eye location & $\mathrm{m}$ & 5.5 \\
\hline Relative soil depth & $\mathrm{m}$ & 120 \\
\hline Overburden pressure & $\mathrm{Pa}$ & $1.177 \mathrm{E}+6$ \\
\hline Pad eye foundation-anchor length & $\mathrm{m}$ & 0.305 \\
\hline Pad eye foundation-anchor width & $\mathrm{m}$ & 0.305 \\
\hline
\end{tabular}

Table 5. Suction caisson design parameters.

\begin{tabular}{|l|l|l|}
\hline Definition & Units & Value: Sim2 \\
\hline Plate width & $\mathrm{m}$ & 2 \\
\hline Plate length & $\mathrm{m}$ & 3.5 \\
\hline Plate thickness & $\mathrm{m}$ & 0.1 \\
\hline Pad eye load & $\mathrm{N}$ & $1.353 \mathrm{E}+6$ \\
\hline Angle & Degrees & 90 \\
\hline Embedded depth & $\mathrm{m}$ & 8.625 \\
\hline Relative soil depth & $\mathrm{m}$ & 120 \\
\hline Overburden pressure & $\mathrm{Pa}$ & $1.177 \mathrm{E}+6$ \\
\hline Pad eye foundation-anchor length & $\mathrm{m}$ & 1.44 \\
\hline Pad eye foundation-anchor width & $\mathrm{m}$ & 0.61 \\
\hline
\end{tabular}

Table 6. Embedded foundation-anchor design parameters.

\begin{tabular}{|l|l|l|l|}
\hline Definition & Units & Value: Sim3 & Value: Sim4 \\
\hline Horizontal Load (x) & N & $-1,088,723$ & $3,977,200$ \\
\hline Horizontal Load (y) & N & $-924,297$ & $-1,387,872$ \\
\hline Vertical Load (z) & N & 205,506 & 965,273 \\
\hline Pile Diameter & m & 3.00 & 3.50 \\
\hline Pile Grout Diameter & m & 0 & 0 \\
\hline Pile Length & m & 6 & 32 \\
\hline Pile Thickness & m & 0.06 & 0.06 \\
\hline Overburden pressure & Pa & $1.177 \mathrm{E}+6$ & $1.177 \mathrm{E}+6$ \\
\hline
\end{tabular}

Table 7. Pile foundation-anchor design parameters.

\begin{tabular}{|l|l|l|l|}
\hline Definition & Units & Value: Sim5 & Value: Sim6 \\
\hline Horizontal Load (x) & N & $-1,088,723$ & $3,977,200$ \\
\hline Horizontal Load (y) & N & $-924,297$ & $-1,387,872$ \\
\hline Vertical Load (z) & N & 205,506 & 965,273 \\
\hline Foundation-anchor Width & m & 12.33 & 18.76 \\
\hline Foundation-anchor Length & m & 12.33 & 18.76 \\
\hline Foundation-anchor Height & m & 0.65 & 1.07 \\
\hline Embedment Depth & m & 1.23 & 1.88 \\
\hline Overburden pressure & Pa & $1.177 \mathrm{E}+6$ & $1.177 \mathrm{E}+6$ \\
\hline Pad eye anchor length & $\mathrm{m}$ & 0.305 & 0.305 \\
\hline Pad eye anchor width & $\mathrm{m}$ & 0.305 & 0.305 \\
\hline
\end{tabular}

Table 8. Shallow gravity foundation-anchor design parameters. 
The material properties used to parameterize the FEA model are shown in Table 9. A0, A1, and A2, are material constants and the coefficients of the polynomial that relates the mean pressure to the yield stress in the soil and crushable foam constitutive model. Specifically, AO defines the soil cohesion and $A 1$ is the slope of the line that defines the conical yield surface when A2 is set to zero. All foundationanchor systems utilized soil properties as shown in Table 4 with identical steel properties.

\begin{tabular}{|l|c|c|c|c|}
\hline Definition & Units & Soft Clay & Dense sand & Steel \\
\hline Density & $\frac{\mathrm{kg}}{\mathrm{m}^{3}}$ & 1,762 & 2,163 & 7,860 \\
\hline Young Modulus & $\mathrm{Pa}$ & $13.41 \mathrm{E}+6$ & $65 \mathrm{E}+6$ & $1.999 \mathrm{E}+11$ \\
\hline Poisson's Ratio & - & 0.45 & 0.35 & 0.3 \\
\hline $\mathrm{A} 0$ & $\mathrm{~Pa}$ & 35910 & 0 & - \\
\hline $\mathrm{A} 1$ & Degrees & 0 & 38.5 & - \\
\hline $\mathrm{A} 2$ & Degrees & 0 & 0 & - \\
\hline Yield Stress & $\mathrm{Pa}$ & - & - & $427.7 \mathrm{E}+6$ \\
\hline
\end{tabular}

Table 9. Material model parameters.

Loading and boundary conditions. The simulation approach implemented the loadings described in the model dimensions and loading levels denoted in Table 5 - Table 8. All foundation-anchor systems applied the pad eye load evenly distributed across pad eye foundation-anchor. This was accomplished by dividing the prescribed load across the respective node surface of the pad eye. The soil mass bottom faces were fixed in the vertical direction, the front cross section faces were fixed normal to their surfaces, and the outer circumferential surfaces of the soil mass were allowed to move only in the vertical orientation. Sierra/SM [6] explicit quasi-static mode solver was utilized for these simulations. A uniform seafloor friction coefficient of 0.5 was implemented in the design studies.

Foundation-anchor verification results. Contour plots of Von Mises stress, Equivalent Plastic Strain (EQPS), and maximum volumetric strain are shown in Figure 6 for the shallow gravity foundationanchor Sim6 design. Non-magnified displacements are shown in this figure. The shallow gravity foundation-anchor results show Von Mises stress of $36 \mathrm{kPa}$ uniformly distributed across the soil volume principally due to the overburden pressure and a significant stress relief on the bottom left of the foundation-anchor load application; a change due to the altered horizontal and vertical load resultant vector. Localized plastic strain is present at the foundation-anchor corners, reaching approximately 1.0 EQPS and averaging approximately 0.5 EQPS in nearby surrounding soft clay bordering the foundation-anchor. The EQPS quickly dissipates to zero around the outer surrounding clay mass. Maximum compressive volumetric strain for the foundation-anchor design reaches 0.03 and occurs in the surrounding foundation-anchor soil. The summarized results for the other five foundation-anchor simulations can be found in the DTOcean report D7.3 [34]. Plastic strain was observed in localized locations around the immediate volume across all foundation-anchor designs.

To compare and summarize performance results across all foundation-anchor simulations, an EQPS ratio of the immediate effected soil volume was taken to that of upper half of the domain modelled, as shown in Figure 5. This metric was used to illuminate the areas of high strain. To determine the proportion of high strain to the overall volume, a ratio metric was used. This metric gives visual and numeric insight into the level of localized strain near the respective foundation, in addition to the rate at which the high strain diminishes in the surrounding volume. As shown in Table 10, all ratios of the effected volume were less than 1 percent to the upper half of the domain, a conservative estimate when compared to the entire domain. A lower threshold value of 0.05 was chosen (except for Sim 2 
with 0.001), where overburden pressure alone in foundation-anchor scenarios caused strain exceeding 0.2 .

(a)

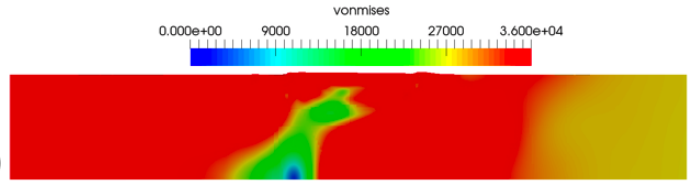

(b)

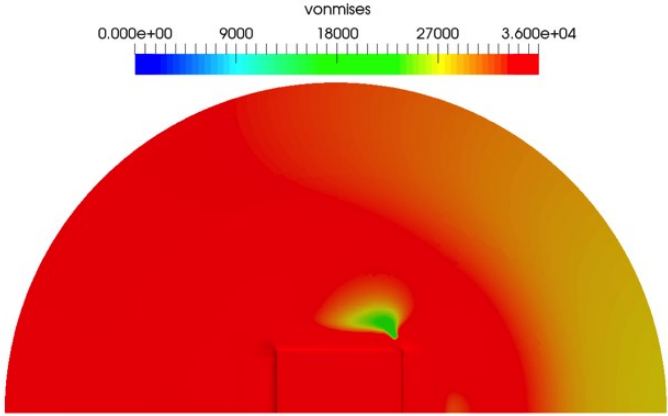

(c)

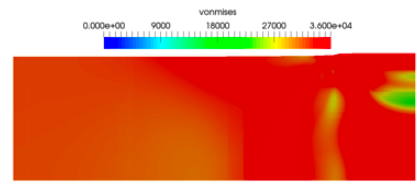

(g)

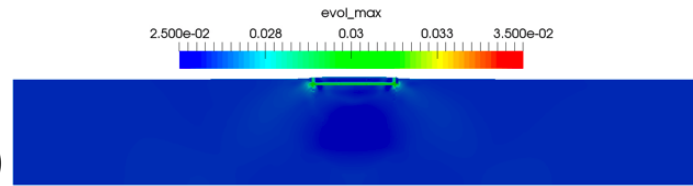

(h)

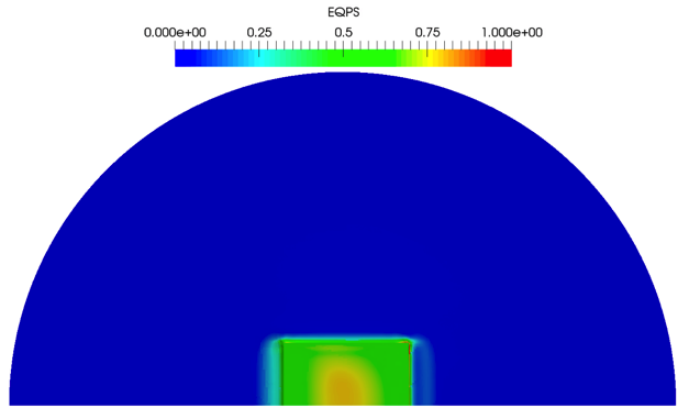

(f)
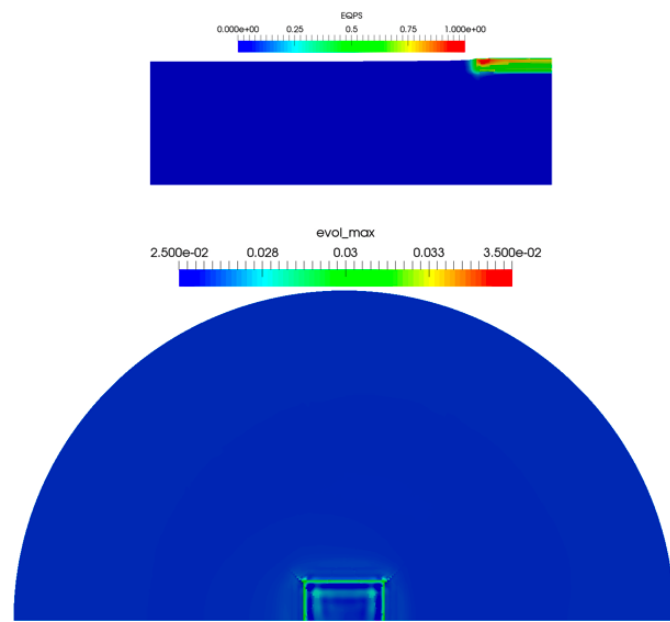

(i)

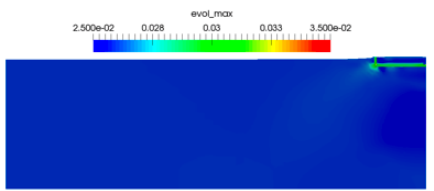

Figure 6. Von Mises stress ( $\mathrm{Pa}$ ) shown in (a) front view (b) plan view and (c) sliced midway through the shallow gravity foundation-anchor Sim6. EQPS shown in (d) front view (e) plan view and (f) sliced midway through the shallow gravity foundation-anchor Sim6. Maximum volumetric strain shown in (g) front view (h) plan view and (i) sliced midway through the shallow gravity foundation-anchor Sim6. 


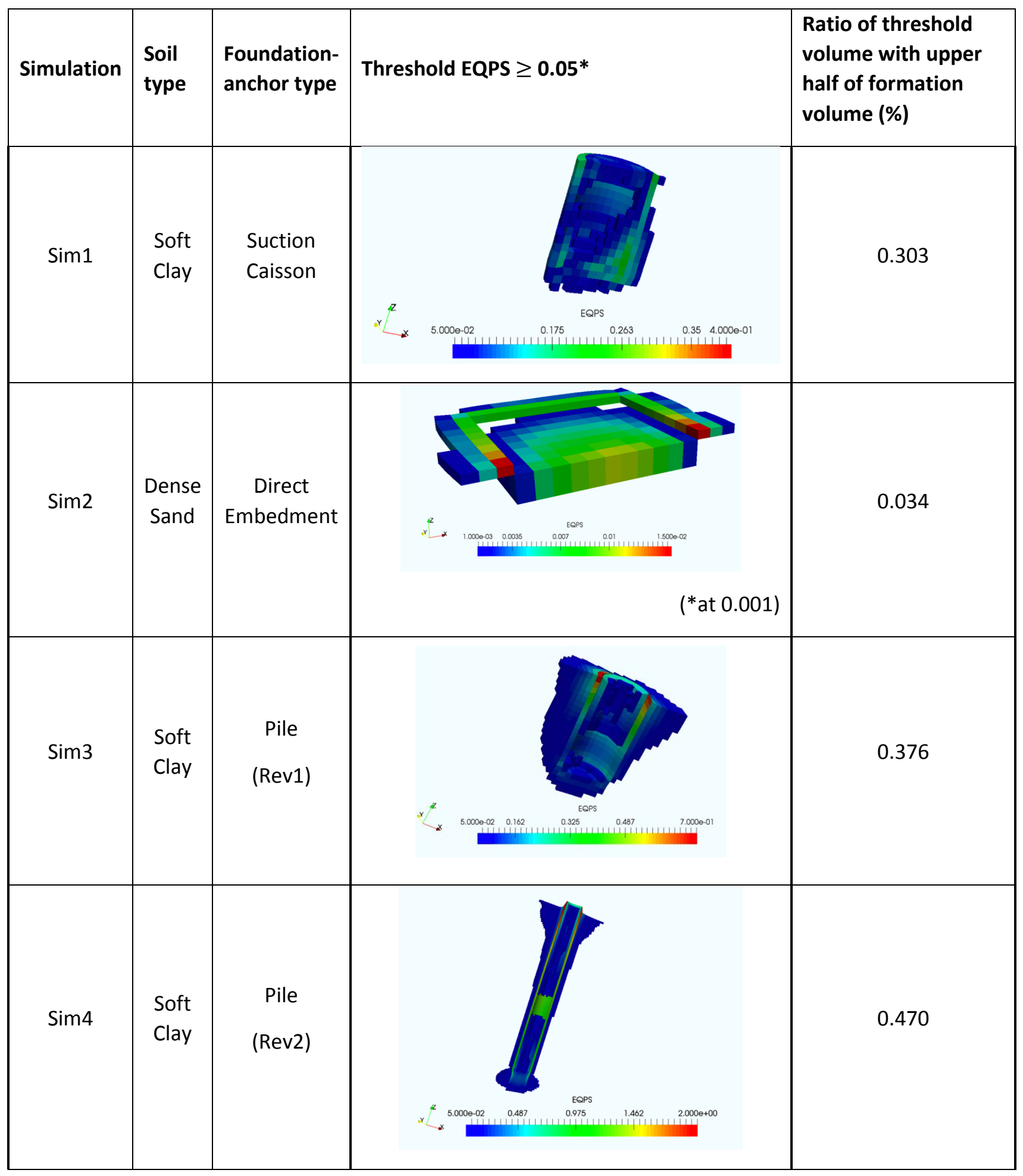




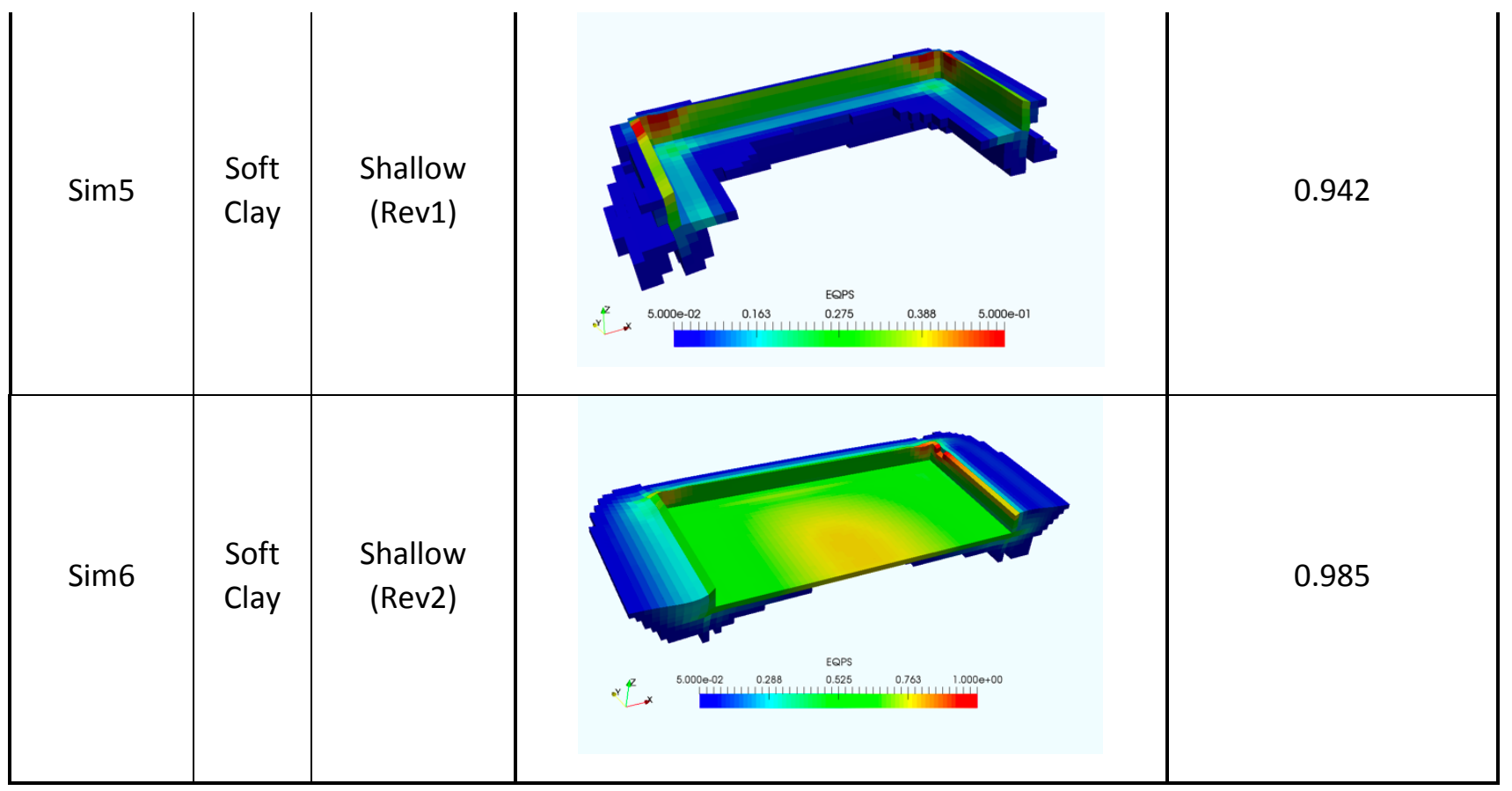

Table 10. Foundation-anchor immediate volume threshold.

\section{Discussion}

\section{Moorings}

Utilising the total environmental loads calculated by the MF module the static analysis produced solutions that were assessed using Orcaflex for both device excursion and fairlead line tensions for ULS and ALS scenarios.

Good agreement $(<10 \%$ line tensions) is noted between the Orcaflex and module results for the highest loaded line in each of the ULS scenarios (Table 3 and Figure 4). This line was removed for ALS analysis, transferring its load to the other lines. For most of the analysed scenarios a similar level of good agreement is noted for the most loaded lines. While large percentage differences are noted for slack and semi-taut lines in both ULS and ALS scenarios, the differences in terms of absolute tension are of a similar magnitude to the maximum loaded line. Agreement is generally poor for very low line tensions and this is due to the different calculation methods used by Orcaflex and the mooring module. Orcaflex uses a lumped-mass method [37] where the line is able to deform in three dimensions. The catenary equations used by the mooring module assume that the line stays on a twodimensional plane between the fairlead and foundation, hence when a line is slack it is possible that the line will have a different geometry, a different length of line resting on the seafloor and therefore a different line tension. Closer agreement for all line tensions would of course be preferable. However as a high level design tool (and precursor to detailed dynamic analysis following recommended practices e.g. [12]), the module satisfies the requirement to adequately estimate the highest design loads as these represent the largest forces expected from extreme environmental conditions at the site.

\section{Foundations}

The suction caisson, direct embedment foundation-anchor, shallow gravity foundation-anchor and pile foundation-anchor designs show localized stress and strain under the prescribed loading conditions, but the respective dense sand soil and soft clay soil masses do not fail throughout the soil volume. The proposed designs provide adequate foundation-anchor systems for the respective load 
scenarios proposed. This analysis demonstrates that the simplified solutions given by the MF module provide an adequate design for estimating costs and performing a relative cost analysis. Neither the solutions generated by the MF module nor the verification work done by the FEA's are intended as a final design. To obtain a finalized design, a more extensive FEA would need to be performed using better material models and higher certainty of material model parameters that are based on actual field data.

\section{Conclusions}

The DTOcean Tool is a system-level software package which can be used to carry out high-level scoping studies of MRE device arrays encompassing several key design aspects and able to determine the feasibility of identified solutions in terms of project economics, system reliability and environmental impact. The MF module is one of the integrated Tool modules which can be used to identify potential mooring and/or foundation systems for a given set of user-defined parameters relating to the site, device(s) and role of the mooring and/or foundation system. This paper has introduced the functionality of the MF module and provide insight into the process of verifying module outputs with relevant commercial software. The module has demonstrated an acceptable level of accuracy in the context of the basic mooring and foundation load analysis necessary for the initial design identification as a forerunner to more detailed analysis.

\section{Acknowledgements}

S.D. Weller, J. Hardwick, N. Mclean and L. Johanning were funded from the European Community's Seventh Framework Programme for DTOcean Project, Grant agreement number: 608597.

S. Gomez, J. Heath, R. Jensen, and J. Roberts were funded by the Department of Energy's (DOE) Energy Efficiency and Renewable Energy (EERE) Program's Wind and Water Power Technologies Office. Sandia National Laboratories is a multi-program laboratory managed and operated by Sandia Corporation, a wholly owned subsidiary of Lockheed Martin Corporation, for the U.S. Department of Energy's National Nuclear Security Administration under contract DE-AC04-94AL85000. SAND Number: 2013-6867 C

\section{References}

[1] Department for Business, Energy \& Industrial Strategy, UK Government. Wave and tidal energy: part of the UK's energy mix; 2013.

[2] Energy Technologies Institute. Wave Energy. Insights from the Energy Technologies Institute; 2015.

[3] Ocean Energy Forum. Ocean Energy Strategic Roadmap. Building Ocean Energy for Europe; 2016.

[4] European Commission. DTOcean Optimal Design Tools for Ocean Energy Arrays [Internet]. Strategic Energy Technologies Information System [cited 15-01-2017]. Available from: https://setis.ec.europa.eu/dt-ocean/

[5] Tension Technology International. OPTIMOOR Mooring Analysis Software for Ships \& Barges [Internet]. Tension Technology International [cited 24-03-2017]. Available from: https://www.tensiontech.com/_app_/resources/documents/www.tensiontech.com/TN01_Optimoo r.pdf 
[6] DHI. SI-Ocean Tidal \& Wave Energy map [Internet]. DHI [cited: 24-03-2017]. Available from: http://si-ocean.dhigroup.com/map.

[7] Orcina. OrcaFlex [Internet]. Orcina [cited: 01-12-2016]. Available from: https://www.orcina.com/SoftwareProducts/OrcaFlex/index.php

[8] Blacker T, Owen SJ, Staten ML et al. CUBIT Geometry and Mesh Generation Toolkit 15.2 User Documentation. SAND Report 2016-1649 R. Sandia National Laboratories, Albuquerque, NM and Livermore; 2016.

[9] SIERRA Solid Mechanics Team. Sierra/SolidMechanics 4.40 User's Guide. SAND Report 20162707. Sandia National Laboratories, Albuquerque, NM and Livermore, CA; 2016.

[10] DTOcean. DTOcean User Manual (Release); 2016.

[11] DTOcean. DTOcean Technical Manual (Release); 2016.

[12] Det Norske Veritas. Position Mooring: DNV-OS-E301; 2015.

[13] Chakrabarti S. Handbook of Offshore Engineering. Oxford, UK: Elsevier; 2005.

[14] Hogben N and Standing RG. Wave loads on large bodies. International Symposium of Dynamic Marine Vehicle Structures in Water; London, UK; 1974.

[15] Wilson JF. Dynamics of Offshore Structures. Hoboken, USA: John Wiley \& Sons, Inc; 2003.

[16] McCamy R and Fuchs R. Wave forces on piles: a diffraction theory. Tech. Memo No. 69. U.S. Army Corps of Engrs; 1954.

[17] Oortmerssen V. The Interaction between a Vertical Cylinder and Regular Waves. Symposium on Offshore Hydrodynamics; Wageningen, Netherlands; 1971.

[18] McCormick ME. Ocean Engineering Mechanics: With Applications. Cambridge, UK: Cambridge University Press; 2010.

[19] McCormick ME and Cerquetti J. Alternative Wave-Induced Force and Moment Expressions for a Fixed, Vertical, Truncated, Circular Cylinder in Waters of Finite Depth. 23rd International Conference on Offshore Mechanics and Arctic Engineering; Vancouver, Canada; 2004.

[20] Journée JMJ and Massie WW. Offshore Hydromechanics. Delft, Netherlands; Delft University of Technology; 2001.

[21] Faltinsen OM. Sea loads on ships and offshore structures. Cambridge, UK; Cambridge University Press; 1990.

[22] Mclver P. Mean drift forces on arrays of bodies due to incident long waves. Journal of Fluid Mechanics. 1987; 185: 469-482.

[23] Eatock Taylor R, Hu CS and Nielsen FG. Mean drift forces on a slowly advancing vertical cylinder in long waves. Applied Ocean Research. 1990; 12 (3): 141-152.

[24] Remery GFM and Hermans AJ. The slow drift oscillations of a moored object in random seas. Journal of the Society of Petroleum Engineering 1972; 12: 191-199.

[25] Det Norske Veritas. Environmental Conditions and Environmental Loads: DNV-RP-C205; 2014. 
[26] EDSU. Fluid forces, pressures and moments on rectangular blocks: ESDU 71016; 1978.

[27] Masciola MD .Instructional and Theory Guide to the Mooring Analysis Program. Phase I: The Multi-Segmented Quasi-Static Model; 2013.

[28] Thompson D and Beasley DJ. SP-2209-OCN Handbook for Marine Geotechnical Engineering. Naval Facilities Engineering Command Port, Hueneme, CA; 2012.

[29] Taiebat HA and Carter JP. Interaction of forces on caissons in undrained soils. 15th International Offshore and Polar Engineering Conference; Seoul, Korea; 2005.

[30] Randolph M and Gourvenec S. Offshore geotechnical engineering. CRC Press; Oxford, UK; 2011.

[31] Deng W, Carter JP and Taiebat HA. Prediction of the lateral capacity of suction caissons. Computer Methods and Advances in Geomechanics: Proceedings of the 10th International Conference on Computer Methods and Advances in Geomechanics; Tucson, USA; 2000.

[32] Det Norske Veritas. Design and Installation of Fluke Anchors: DNV-RP-E301; 2012.

[33] Det Norske Veritas. Design and installation of plate anchors in clay: DNV-RP-E302; 2002.

[34] DTOcean. Analysis of Ocean Energy Arrays: application to real case studies, validation and optimisation. Deliverable 7.3 of the DTOcean project; 2016.

[35] Krieg RD. A Simple Constitutive Description for Soils and Crushable Foams. SC-DR-72-0883. Sandia National Laboratories, Albuquerque, NM and Livermore, CA; 1978.

[36] Taylor LM and Flanagan DP. Pronto 3D A Three-Dimensional Transient Solid Dynamics Program: SAND87-1912. Sandia National Laboratories, Albuquerque, NM and Livermore, CA; 1989.

[37] Orcina. Orcaflex Documentation [Internet]. Orcina [cited: 11-10-2016]. Available from: https://www.orcina.com/SoftwareProducts/OrcaFlex/Documentation/Help/ 